\title{
ODONTOLOGÍA SANMARQUINA
}

ISSN: 1560-9111

Vol. 10 № 2 - 2007

\section{Editorial}

\section{Estimados colegas}

En esta oportunidad es satisfactorio comentar con ustedes algunos eventos de importancia que se han venido desarrollando, en el quehacer del área de investigación, en este último semestre del año en curso.

Es necesario destacar un evento de relevancia que contribuirá a mejorar la visibilidad en el ámbito internacional de todas las revistas de investigación de nuestra Universidad y dentro de ellas la nuestra ODONTOLOGÍA SANMARQUINA, mejorando su difusión y ampliando su alcance a nivel mundial, oportunidad que podrá ser efectiva gracias a la reciente firma de un contrato de licencia entre San Marcos y Gale Group, filial de Thomson Corporation, una de las mas importantes empresas de información científica electrónica a nivel mundial. Las revistas serán difundidas a través del portal "Informe Académico", el cual en la actualidad se encuentra en un proceso de desarrollo, es una base de datos en español diseñada para satisfacer las necesidades de investigación de los usuarios hispano-parlantes, que difunde artículos en texto completo de las publicaciones periódicas académicas en español mas reconocidas. Cabe notar que éste contrato no implica exclusividad, por lo que las publicaciones periódicas pueden difundirse igualmente por otros medios electrónicos. Además, el material publicado en nuestras revistas será incluido en las diversas bases de datos que forman parte de ésta importante empresa de información científica.

Otroevento importante a comentar lo constituye la realización de la "Primera Feria de Transferencia e Innovación Tecnológica", llevada a cabo en los ambientes de la Facultad de Medicina Veterinaria, los días 19 al 21 de julio del presente año, con la finalidad de dar a conocer los resultados de los proyectos de investigación innovadores que se han desarrollado últimamente en las facultades de la Universidad, así como, exhibir productos y servicios que brindan las facultades de la universidad (servicios de investigación, de laboratorios, consultarías, de capacitación, de software, etc.), a los sectores interesados de la sociedad, tales como empresas públicas y privadas, gobiernos regionales y locales, comunidades nativas y campesinas, instituciones científicas y culturales, organismos no gubernamentales, estudiantes y público en general.

El evento contó con el auspicio de instituciones representativas de la sociedad, entre ellas: el Consejo Nacional de Ciencia, Tecnología e Innovación Tecnológica (CONCYTEC), Sociedad Nacional de Industrias, Cámara de Comercio de Lima, Asociación de Exportadores.

A este respecto la participación de nuestro Instituto de Investigación tuvo una entusiasta y destacada participación, con cuatro proyectos de investigación ejecutados el año anterior, llegando a obtener un Segundo puesto en el premio a la Innovacion, con la investigación titulada: Fortalecimiento de la salud bucal con metodología didáctica lúdica "DENTOPLAY", a cargo de las investigadoras: Mg. Margot Gutiérrez Ilave, C.D. Lita Ortiz y los alumnos: Jeannette Albino, Sergio Castillo.

\section{La Directora}

